\title{
Parallel Pathways Can Conduct Visual CS Information During Classical Conditioning of the NM Response
}

\author{
Olga Koutalidis, Amy Foster, and Donald J. Weisz \\ Department of Psychology, Yale University, New Haven, Connecticut 06520
}

\begin{abstract}
Single and combined lesions were made to the lateral geniculate nucleus (LGN), the superficial layers of the superior colliculus (SC), and the pretectal nuclei (Ptc) prior to conditioning of the nictitating membrane (NM) response in rabbit with a visual conditioned stimulus (CS). Due to technical considerations, lesions of the dorsal LGN were accompanied by lesions of the visual cortex, the only output of the dorsal LGN, in order to render the dorsal LGN nonfunctional. Single lesions to any one of the 3 target systems (LGN, SC, Ptc) did not alter the rate of conditioning. Furthermore, double lesions to any 2 of the systems did not prevent conditioning, although LGN + SC lesions significantly retarded acquisition. When all 3 systems were lesioned, however, animals never acquired to the visual CS, although they successfully conditioned to an auditory CS. The results indicate that in rabbit there are parallel visual pathways individually capable of supporting the acquisition of conditioned NM responses.
\end{abstract}

Over the past few years there has been much progress in identifying the neural circuit underlying classical conditioning of the nictitating membrane (NM) response in rabbit. Several structures, such as the interpositus nucleus of the cerebellum, the red nucleus, and the pontine nuclei, have been identified as critical for acquisition of the NM conditioned response (McCormick et al., 1982; Yeo et al., 1982, 1985a; Haley et al., 1983; McCormick and Thompson, 1983; Rosenfield and Moore, 1983; Lavond et al., 1984b; Rosenfield et al., 1985; Lewis et al., 1987). In addition, there has been much progress in determining the unconditioned reflex pathway (Cegavske et al., 1976; Berthier and Moore, 1983; Harvey et al., 1984; Disterhoft et al., 1985).

On the basis of these findings, Thompson and colleagues have proposed a neural circuit underlying NM response conditioning (McCormick and Thompson, 1983; Steinmetz et al., 1985b; Woodruff-Pak and Thompson, 1985). According to this model, which is consistent with the Marr-Albus theory of cerebellar function (Marr, 1969; Albus, 1971), sensory information regarding the unconditioned stimulus (US) is projected from the trigeminal nucleus to the inferior olive and then, via climbing fibers (in the inferior cerebellar peduncle), to the cerebellum. Information about the conditioned stimulus (CS) is projected to the cerebellum via mossy fibers (in the middle cerebellar peduncle). The convergence of the US and CS in the cerebellum, either in the deep cerebellar nuclei and/or in the cerebellar cor-

\footnotetext{
Received Aug. 26, 1986; accepted July 16, 1987.

Correspondence should be addressed to Donald J. Weisz, Department of Psychology, P.O. Box 11A, Yale Station, New Haven, CT 06520.

Copyright (C) 1988 Society for Neuroscience $0270-6474 / 88 / 020417-11 \$ 02.00 / 0$
}

tex, is thought to be critical for NM conditioning. The cerebellar activity, in turn, is projected via the superior cerebellar peduncle to the red nucleus and then to the accessory abducens nucleus, which controls the NM response.

While much is known about both the unconditioned and the conditioned response pathways, there is relatively little information regarding CS pathways. Skelton et al. (1984) showed that large lesions of the superior colliculus and adjacent structures partially disrupted retention of NM conditioning to a visual CS without affecting conditioning to an auditory CS. Lavond et al. (1984a) showed that injection of lidocaine into the lateral lemniscus (at its exit from the superior olive) abolished NM conditioning to an auditory CS but not to a visual CS. In addition, Steinmetz et al. (1986) found that lesions of the dorsolateral pontine nucleus (DLPN) abolished conditioned responding to an auditory CS but not to a visual CS. Despite these important findings, the tracing of CS pathways is still fragmentary.

Identification of the CS pathway has important implications. First, in order to complete the circuit underlying NM conditioning, the CS pathway needs to be linked to those central brain structures, such as the cerebellum and red nucleus, that have already been identified as components of the conditioned NM response circuit. Second, the possibility of learning-dependent changes within the CS pathway needs to be explored. This information would permit a more accurate interpretation of any neuronal changes in the cerebellum and red nucleus during NM conditioning.

The CSs used in NM conditioning are generally either visual or auditory; consequently, the choice of which CS pathway to investigate was between the corresponding neural systems. The present study investigates the visual system for 2 primary reasons. First, the anatomical location of most visual structures facilitates the use of both lesion and recording techniques. This contrasts with the auditory system, where lesions of brain-stem auditory structures are very difficult without severely disrupting the motor coordination of the animals (unpublished observations). Second, the functional anatomy of most visual structures and the specific characteristics of individual cells have been studied extensively in rabbit.

The aim of the present study was to identify the visual structures necessary for the acquisition of NM conditioned responses when light is used as the CS. The focus was on those visual structures that receive direct input from the retina: the lateral geniculate nucleus (LGN), the superficial layers (stratum griseum superficiale and stratum opticum) of the superior colliculus (SC), and the pretectal nuclei (Ptc). Although the LGN is composed of 2 divisions (dorsal and ventral), and the Ptc of 4 nuclei (anterior and posterior pretectal nuclei, nucleus of the 
Figure 1. Mean number of days to $70 \%$ criterion. Groups are plotted on the abscissa, and days to criterion are plotted on the ordinate. The SEM is plotted for each group. Asterisks indicate groups that were significantly different from controls.

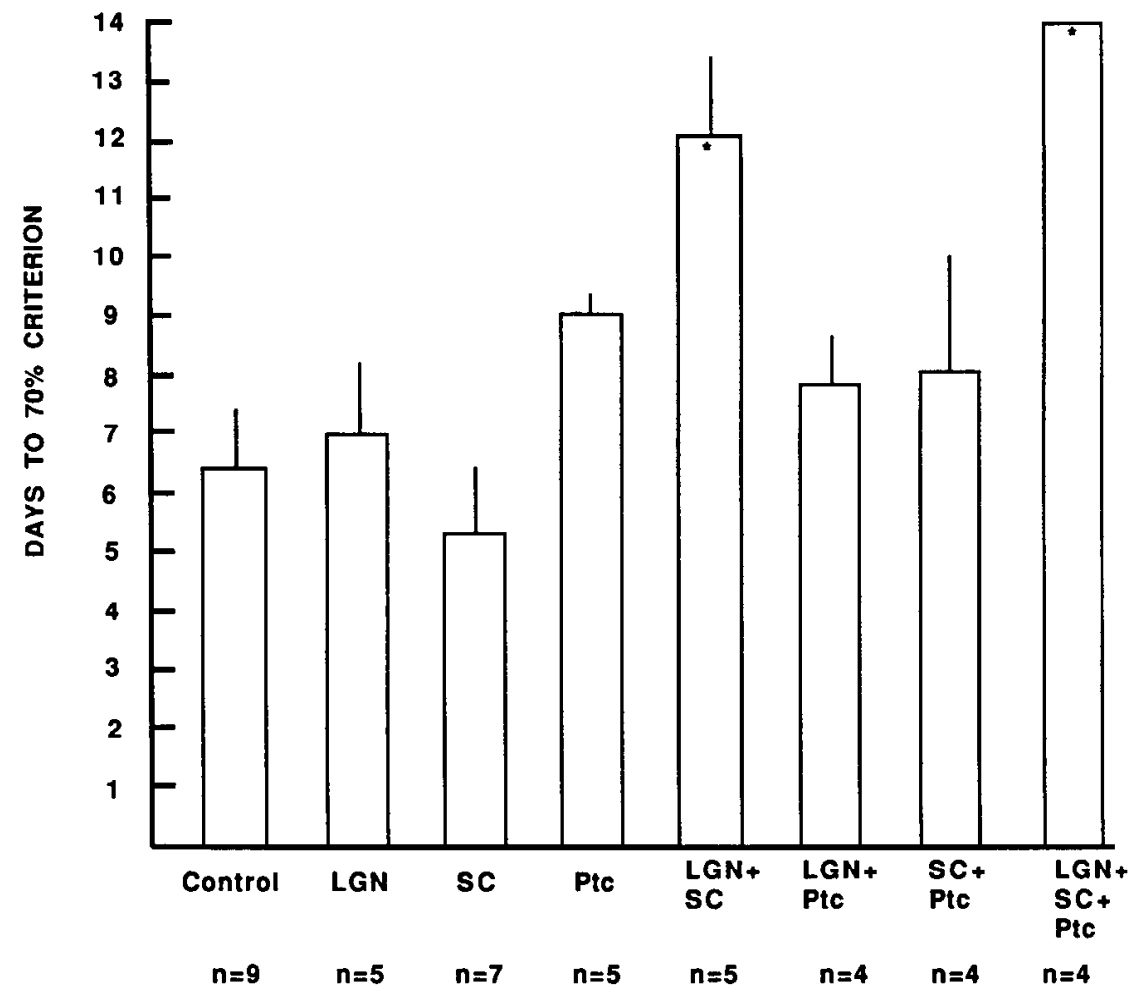

optic tract, and the olivary nucleus), the LGN and Ptc were treated as 2 unitary structures because of the close physical proximity of the various divisions. The decision served in reducing to 8 the number of possible lesion combinations.

\section{Materials and Methods}

Subjects. Forty-three male, New Zealand white rabbits weighing 2.2$2.8 \mathrm{~kg}$ were used as subjects. Animals were housed individually and maintained ad libitum on food and water. The animal colony was lighted from 7:00 a.m. to 7:00 p.m.

Surgical procedures. There were 8 groups: (1) LGN $(n=5),(2) \mathrm{SC}$ $(n=7),(3) \operatorname{Ptc}(n=5),(4) \mathrm{LGN}+\mathrm{SC}(n=5),(5) \mathrm{LGN}+\operatorname{Ptc}(n=4)$,
(6) $\mathrm{SC}+\operatorname{Ptc}(n=4),(7) \mathrm{LGN}+\mathrm{SC}+\operatorname{Ptc}(n=4)$, and (8) control $(n=$ 9). The 3 primary visual structures (LGN, SC, Ptc) were lesioned 1 at a time, 2 at a time, or all 3 in combination. In addition, the visual cortex was lesioned in all cases that a lesion was aimed at the LGN. Although lesions at the ventral LGN were successful, it was technically impossible to make lesions of appropriate size at the dorsal LGN. Since the dorsal LGN projects exclusively to the visual cortex, lesions of the latter were made in order to render dorsal LGN nonfunctional. The lesion of the visual cortex included both visual area 1 and visual area 2 according to the distinction made in rabbit by Thompson et al. (1950). Preliminary work showed that lesions of the visual cortex alone had no effect on acquisition of NM conditioning to a visual CS.

The technical difficulties associated with lesions of the dorsal LGN were as follows. Both electrolytic and chemical lesions were attempted.
Figure 2. Acquisition curves are depicted for each group. Animals were trained until they reached the $70 \%$ acquisition criterion. Once an animal reached criterion, a score of $70 \%$ was assigned for that day and all subsequent days.

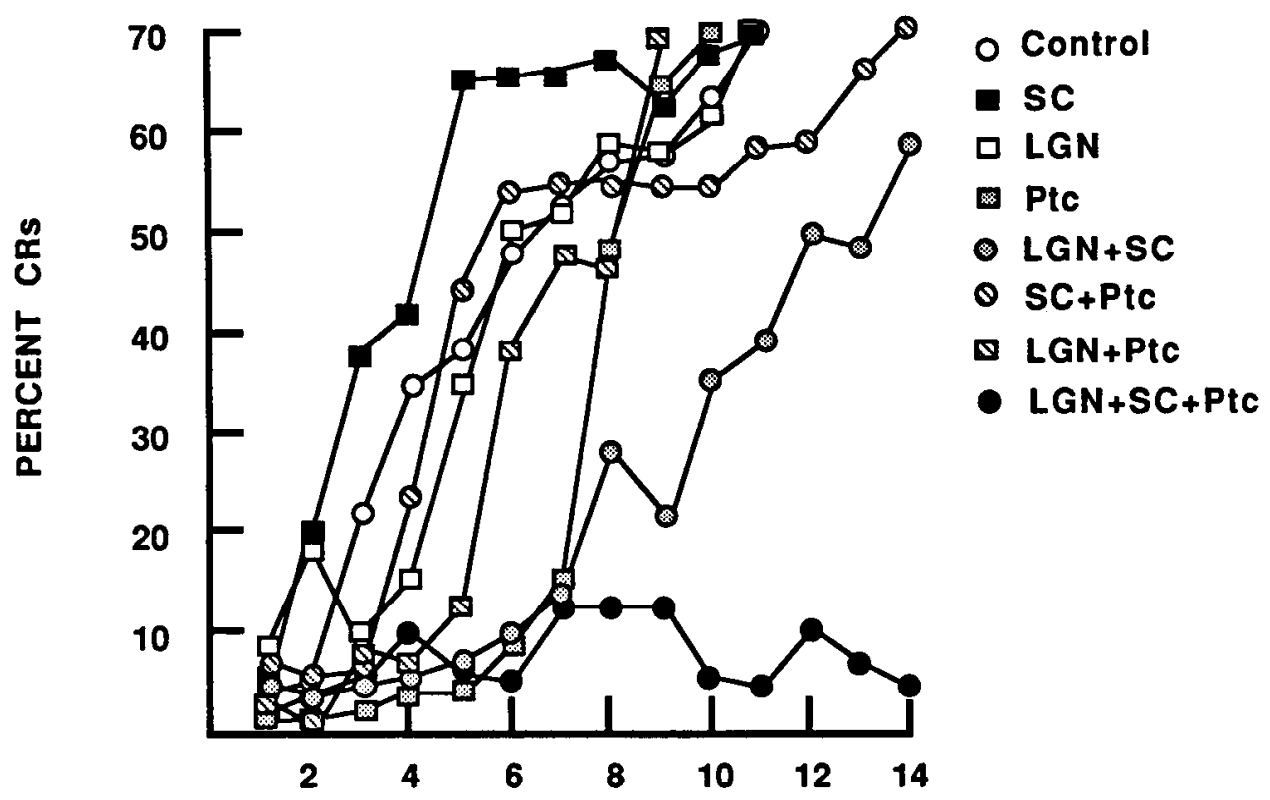




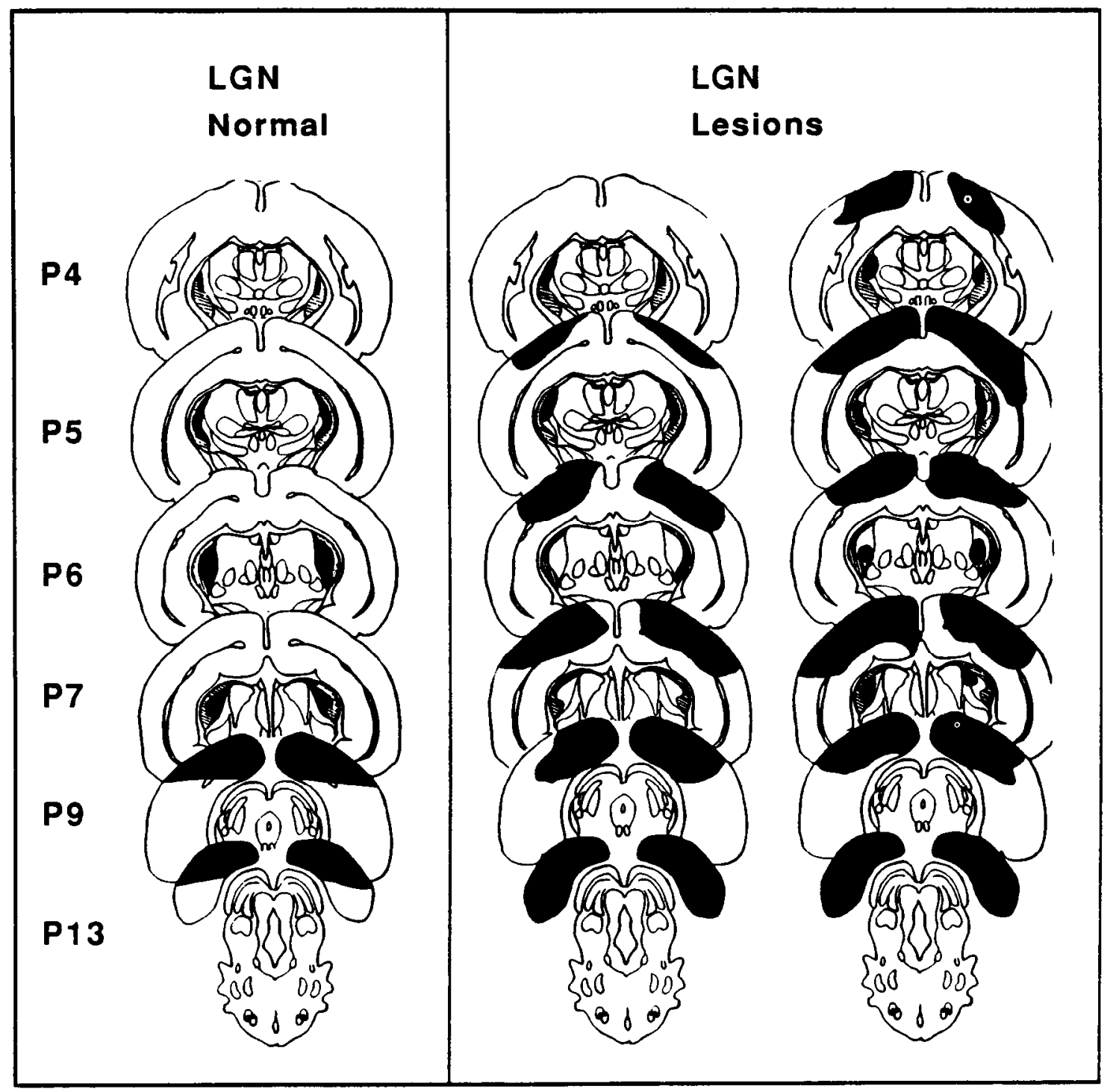

Figure 3. Histological reconstructions of LGN lesions. The column labeled $L G N$ Normal shows the LGN and visual cortex (black) in an intact animal. Columns labeled LGN Lesions show the smallest and largest lesions (black) in the LGN group. The labels (e.g., P7) on this and subsequent figures indicate the distance (in $\mathrm{mm}$ ) that each section is posterior to bregma.

Electrolytic lesions spread beyond the dorsal LGN, resulting in considerable disruption of adjacent structures and fibers of passage (unpublished observations). Chemical lesions were made with ibotenic acid, which has the property of destroying only cell bodies while leaving fibers of passage intact. Ibotenic acid lesions were more successful in that they were very localized. However, animals that received large ibotenic acid lesions at the dorsal LGN did not survive the surgical procedure. Even if injections were made in stages, more than $25 \mu \mathrm{g}$ of acid produced severe motor disabilities or death in the animals. $\Lambda \mathrm{n}$ injection of $25 \mu \mathrm{g}$ was not sufficient to disrupt both ventral and dorsal divisions.

At the time of surgery, each animal was anesthetized via a subcutaneous injection of chlorpromazine $(10 \mathrm{mg} / \mathrm{kg})$, followed $1 \mathrm{hr}$ later by an injection of sodium pentobarbital $(22 \mathrm{mg} / \mathrm{kg})$. Additional injections of sodium pentobarbital were administered as needed to maintain surgical anesthesia. Corneal and leg reflexes were monitored to insure that deep anesthesia was maintained. The rabbit was placed on a custom stereotaxic headholder. The skull was exposed by making a midline scalp incision and retracting the scalp and periosteum. The skull was cleaned with hydrogen peroxide, and holes were drilled through the skull at points dorsal to the structures to be lesioned.

All lesions were bilateral. In general, multiple injections were made in each structure, with no more than $0.5 \mu \mathrm{l}$ of acid injected at any single injection site. The ventral LGN and dorsal LGN were lesioned by in- jecting a total of 10 and $15 \mu \mathrm{g} / 1.5 \mu \mathrm{l}$ of ibotenic acid, respectively, on each side of the brain. The Ptc was also lesioned with ibotenic acid (25 $\mu \mathrm{g} / 2.5 \mu \mathrm{l}$ on each side). The visual cortex and the SC (superficial layers) were lesioned by aspiration. Preliminary work revealed that lesioning the SC (superficial layers) either by injection of ibotenic acid or by passing anodal current produced relatively small lesions of the structure. Aspiration permitted an almost complete removal of the SC (superficial layers). This technique, however, required the removal of overlying cortex in order to provide access to the SC. Although effort was taken to minimize damage to overlying visual cortex, there was always damage to the caudal part of this area.

Following the lesions, a headstage was mounted on the skull with dental acrylic and supporting screws. Panalog ointment was applied to the skull and to the area of the scalp incision to prevent infection. The incision was closed around the headstage with ny!on sutures. As an added protection against infection, intramuscular injections of Bicillin $(300,000 \mathrm{U})$ were given following surgery.

Behavioral procedures. The apparatus and methods used for conditioning are basically those described by Gormezano and colleagues (1962). Animals were conditioned in a sound attenuated and ventilated chamber. Each rabbit was restrained in a Plexiglas box with an adjustable ear plate and ear clamp securing the head and a second plate over the animal's back to restrict general body movement. A small nylon loop, 
Figure 4. Histological reconstructions of SC lesions. The column labeled $S C$ Normal shows the SC (black) in an intact animal. Columns labeled SC Lesions show the smallest and largest lesions (black) in the SC group.

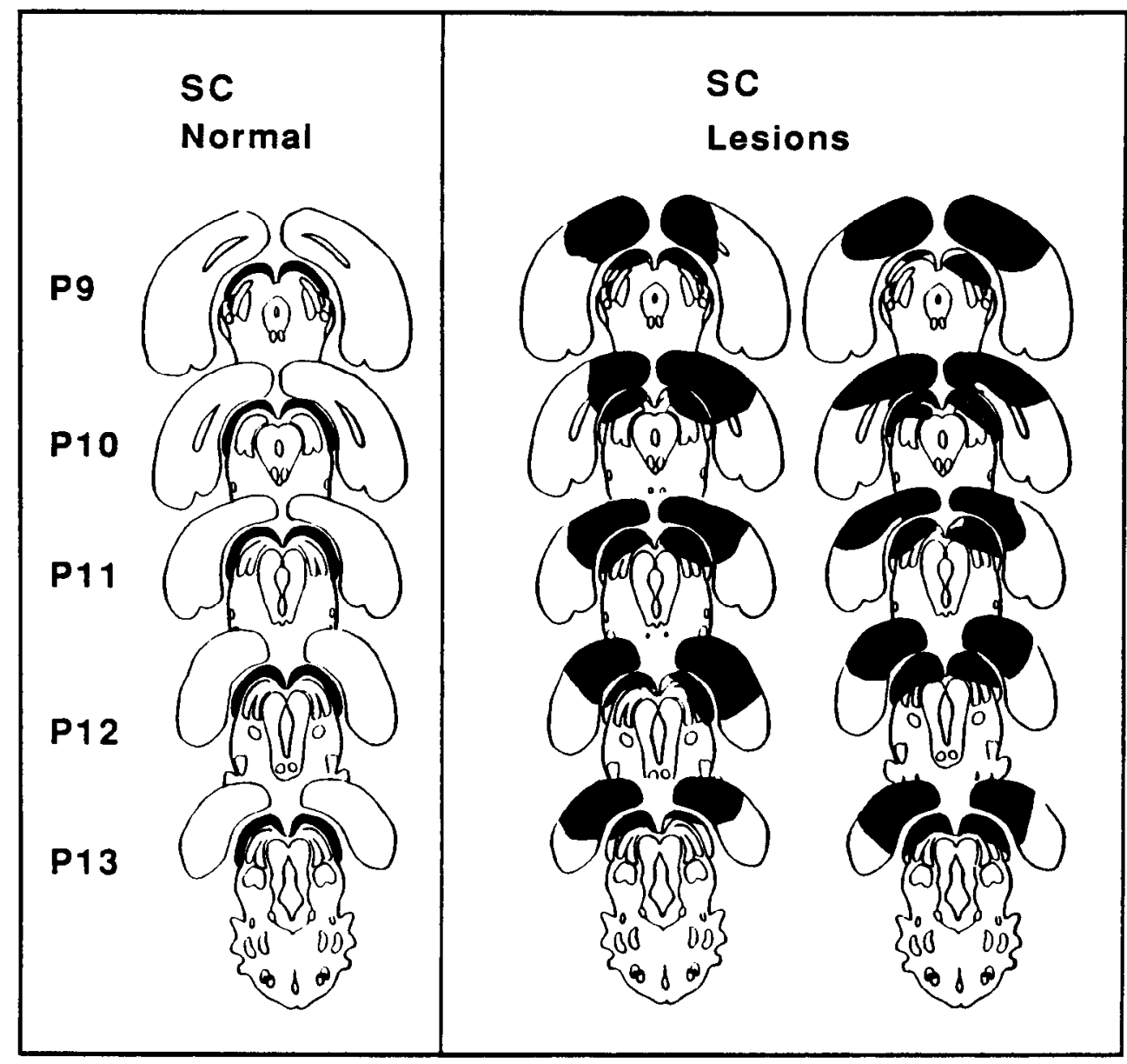

sutured through the animal's NM, was attached to the shaft of a rotary phototransducer, which, in turn, was connected to a headgear mounted on top of the animal's head. In this way, lateral movement of the NM was transduced into a DC signal that was monitored on an oscilloscope and recorded on tape.

The CS was either a $600 \mathrm{msec}$ light (wholc-ficld illumination, $281 \times$ ) or a $600 \mathrm{msec}$ white noise $(60 \mathrm{~dB})$. These stimuli were presented through a white screen $(2 \times 2 \mathrm{~cm})$, or a speaker, respectively, located $12 \mathrm{~cm}$ directly in front of the animal. The UCS was a corneal air puff (100 $\mathrm{msec}$ ) delivered from a gate pressurized to $3 \mathrm{psi}$. The interstimulus interval was $500 \mathrm{msec}$ with the CS and UCS coterminating. The intertrial intervals varied randomly from 35 to $45 \mathrm{sec}$ with a mean of 40 sec. The delivery of stimuli was controlled by a programmable, computerized system.

All animals received $2 \mathrm{~d}$ of adaptation in the apparatus prior to training sessions. A training session consisted of 10 blocks, with each block containing one nonreinforced $C S$-alone test trial and 9 paired $C S$. UCS trials. Animals were trained to a criterion of $70 \%$ conditioned responses over a day of training or for a maximum of $14 \mathrm{~d}$. Animals that did not reach acquisition criterion by the 14th $\mathrm{d}$ werc further traincd with an auditory CS (white noise) until they reached criterion. They were then given additional training with the light $\mathrm{CS}$ for $7 \mathrm{~d}$.

Behavioral data were analyzed by an Apple II computer system. Movement of the NM that exceeded $0.5 \mathrm{~mm}$ was considered to be a response. An NM response that occurred during the $500 \mathrm{msec}$ ISI in paired trials or during $500 \mathrm{msec}$ from the CS onset in CS-alone trials was defined as a CR. The maximum amplitudes of the unconditioned responses were also calculated.

Histological procedures. At the conclusion of training, all animals were deeply anesthetized by injection of pentobarbital into the marginal ear vein and then perfused through the heart with saline $(0.9 \%)$ and formalin $(10 \%)$. The brains were stored for a minimum of 1 week in sucrose formalin. The brains were then embedded in albumin gelatin and frozen. Coronal sections were taken through the extent of the lesion at $50 \mu \mathrm{m}$.
The tissue slices were mounted and stained with cresyl violet. Reconstruction of the lesions was accomplished by placing the stained slices on a photographic enlarger and projecting the sections onto plates from the atlas of Urban and Richard (1972). Lesion location was verified using a high-power microscope and camera lucida.

\section{Results}

\section{Behavioral results}

The number of days for each animal to meet criterion (70\% CRs during $\mathrm{l} \mathrm{d}$ of training) was determined, and group means were calculated from these data (Fig. 1). All animals in the control, LGN, SC, Ptc, LGN + Ptc, and SC + Ptc groups met the acquisition criterion within the initial $14 \mathrm{~d}$ of training. Mean number of days to criterion for each group was 6.4 (control), 7.0 (LGN), 5.3 (SC), 9.0 (Ptc), 7.8 (LGN + Ptc), and 8.0 (SC + Ptc) (Fig. 1).

Three (out of five) animals in the LGN + SC group failed to reach criterion during the initial $14 \mathrm{~d}$ of training. These animals reached criterion to the light $\mathrm{CS}$ after they acquired to the white noise CS. Histological examination of the LGN + SC group did not reveal any correlation between the performance of the animals and lesion sites. The mean number of days to criterion for this group was 12.0 (Fig. 1).

Triple lesion animals failed to meet criterion to the light CS during a total of $21 \mathrm{~d}$ of training ( 14 initial days and 7 additional days following acquisition to the white noise CS). All triple lesion animals reached criterion to the white noise $\mathrm{CS}$ with a mean of $7.0 \mathrm{~d}$. 


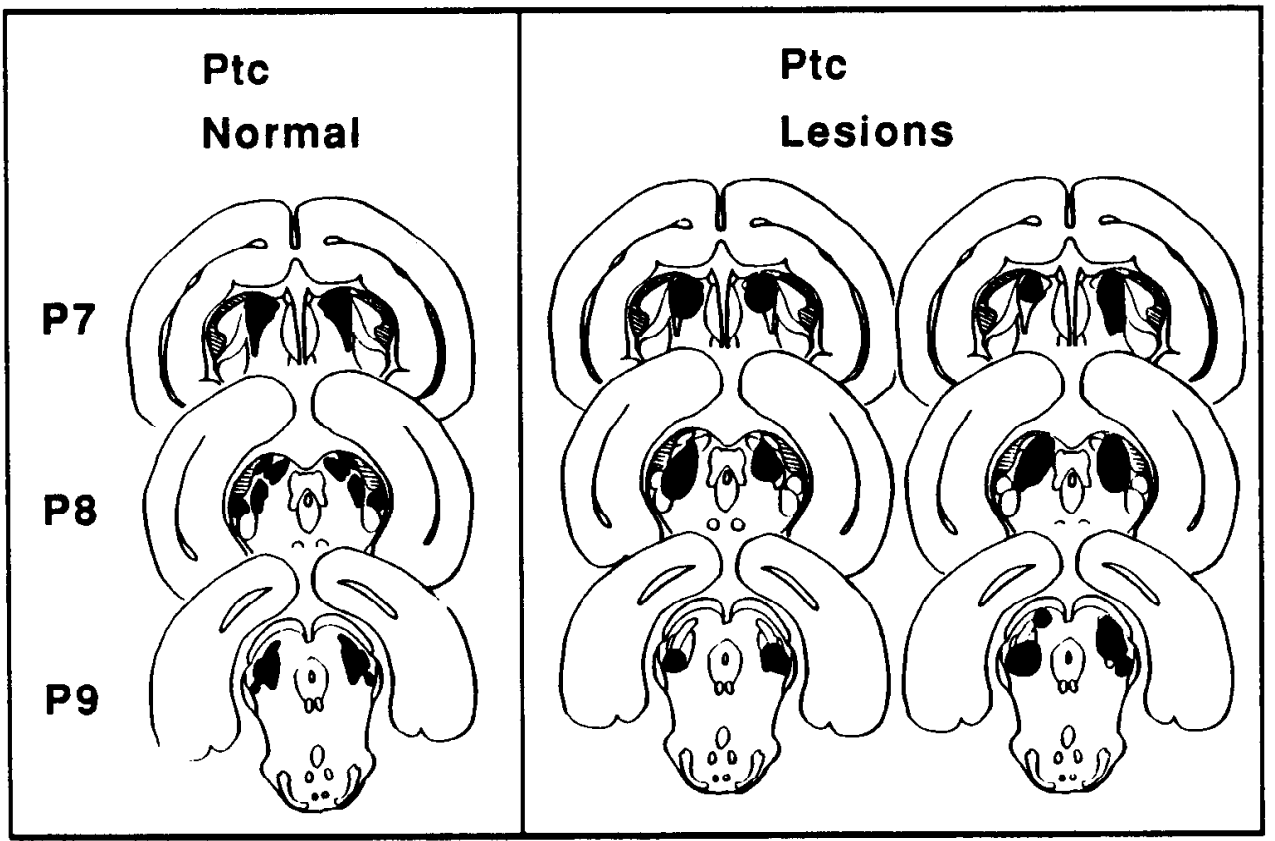

Figure 5. Histological reconstructions of Ptc lesions. The column labeled Ptc Normal shows the Ptc (black) in an intact animal. Columns labeled Ptc Lesions show the smallest and largest lesions (black) in the Ptc group.
A Kruskal-Wallis test was conducted on the number of days to criterion to the light CS of all 8 groups. A nonparametric test was chosen since the distributions violated the assumption of homogeneity of variance. All animals in the triple lesion group failed to reach criterion to the light CS producing a "ceiling effect," and 3 animals in the LGN + SC group reached criterion to the light CS after the 14 initial days of training. Statistically significant differences were found among groups $(H=20.9, d f=$ $7, p<0.01)$. Pairwise comparisons between the control and each other group were subsequently made using the Mann-Whitney $U$ test. The triple lesion group (U1 $=0, \mathrm{U} 2=36,4,9, p<$ $0.01)$ and the $\mathrm{LGN}+\mathrm{SC}$ group $(\mathrm{U} 1=4.5, \mathrm{U} 2=40.5,5,9, p<$ 0.05 ) were found to be significantly different from the control group. No other groups were significantly different from the controls.

As the selection of an acquisition criterion is arbitrary, a second criterion of only $35 \%$ CRs during a day of training was chosen to determine whether a more liberal criterion would be sensitive to the lesions. The mean number of days to the $35 \%$ criterion for each group were 6.0 (control), 5.4 (LGN), 3.7 (SC), 8.0 (Ptc), 10.4 (LGN + SC), 7.0 (LGN + Ptc), 6.8 (SC + Ptc), and 14.0 (triple lesion group). A Kruskal-Wallis test was conducted on the number of days to the $35 \%$ criterion of all 8 groups. Statistically significant differences were found among groups $(H=20.5, d f=7, p<0.01)$. Subsequent Mann-Whitney $U$ tests revealed the same patterns of differences for the $35 \%$ criterion as for the $70 \%$ criterion; that is, the triple lesion group $(\mathrm{U} 1=0, \mathrm{U} 2=36,4,9, p<0.01)$ and the $\mathrm{LGN}+\mathrm{SC}$ group (U1 $=5, \mathrm{U} 2=40,5,9, p<0.05)$ were significantly different from the control group.

The mean number of conditioned responses in each group was determined for each day of training. Because animals were trained for different numbers of days, the percentage of conditioned responses for all days beyond the criterion day was assumed to be $70 \%$ for days plotted. Figure 2 depicts the acquisition curves for each group.

The amplitudes of URs were determined for each animal on the first day of training. Thesc data were used to determine if any lesion reduced an animal's ability to respond. The mean UR amplitude for each group was as follows: control, $8.3 \mathrm{~mm}$; LGN, $10.8 \mathrm{~mm}$; SC, $9.9 \mathrm{~mm}$; Ptc, 6.8; LGN + SC, 9.0; LGN + Ptc, $7.8 \mathrm{~mm}$; SC + Ptc, $9.0 \mathrm{~mm}$; LGN + SC + Ptc, $9.4 \mathrm{~mm}$. Analysis of variance revealed no significant differences among groups in UR amplitudes $(F<1)$.

\section{Histological reconstructions}

Lesion sites were determined for each animal. Percentage of destruction was quantified by overlaying a grid $(0.5 \mathrm{~cm} \times 0.5$ $\mathrm{cm}$ ) on each lesion drawing. The number of squares covered by each lesion was counted and divided by the number of squares covered by the corresponding intact structure. Table 1 shows the mean percentage lesion and range for each group. Figures 3-5 show the smallest and largest lesions of the single lesion groups. Figures 6-8 show the smallest and largest lesions of the double lesion groups. Figure 9 shows the smallest and largest lesions of the triple lesion group. Figures 10 and 11 show photomicrographs of representative ibotenic acid lesions at the ventral LGN and Ptc, respectively. Ibotenic acid destroyed large cells in both structures and created a discrete region of gliosis that can be distinguished in Figures $10 b$ and $11 b$.

As can be seen from Table 1 , injection of ibotenic acid destroyed $80-91 \%$ of the ventral LGN, $21-40 \%$ of the dorsal LGN (only a partial lesion of the dorsal LGN was attempted), and aspiration removed $85-93 \%$ of the visual cortex in the 4 groups that the LGN and visual cortex were the target areas (LGN, $\mathrm{LGN}+\mathrm{SC}, \mathrm{LGN}+\mathrm{Ptc}$, and LGN + SC + Ptc). Aspirative lesions destroyed $84-95 \%$ of the SC (superficial layers) in the 4 groups that the $\mathrm{SC}$ was a target area $(\mathrm{SC}, \mathrm{LGN}+\mathrm{SC}, \mathrm{SC}+\mathrm{Ptc}$, and $\mathrm{LGN}+\mathrm{SC}+\mathrm{Ptc}$ ). Injection of ibotenic acid destroyed 72$79 \%$ of the Ptc in the 4 groups that the Ptc was a target area (Ptc, LGN + Ptc, SC + Ptc, and LGN + SC + Ptc).

These results indicate that lesions were large, as they covered (on the average) $85 \%$ of the target areas. They also indicate that similar lesions were made to the LGN, SC, and Ptc across the various combinations of single, double, and triple lesions, in that the variation among groups was approximately only $10 \%$. 


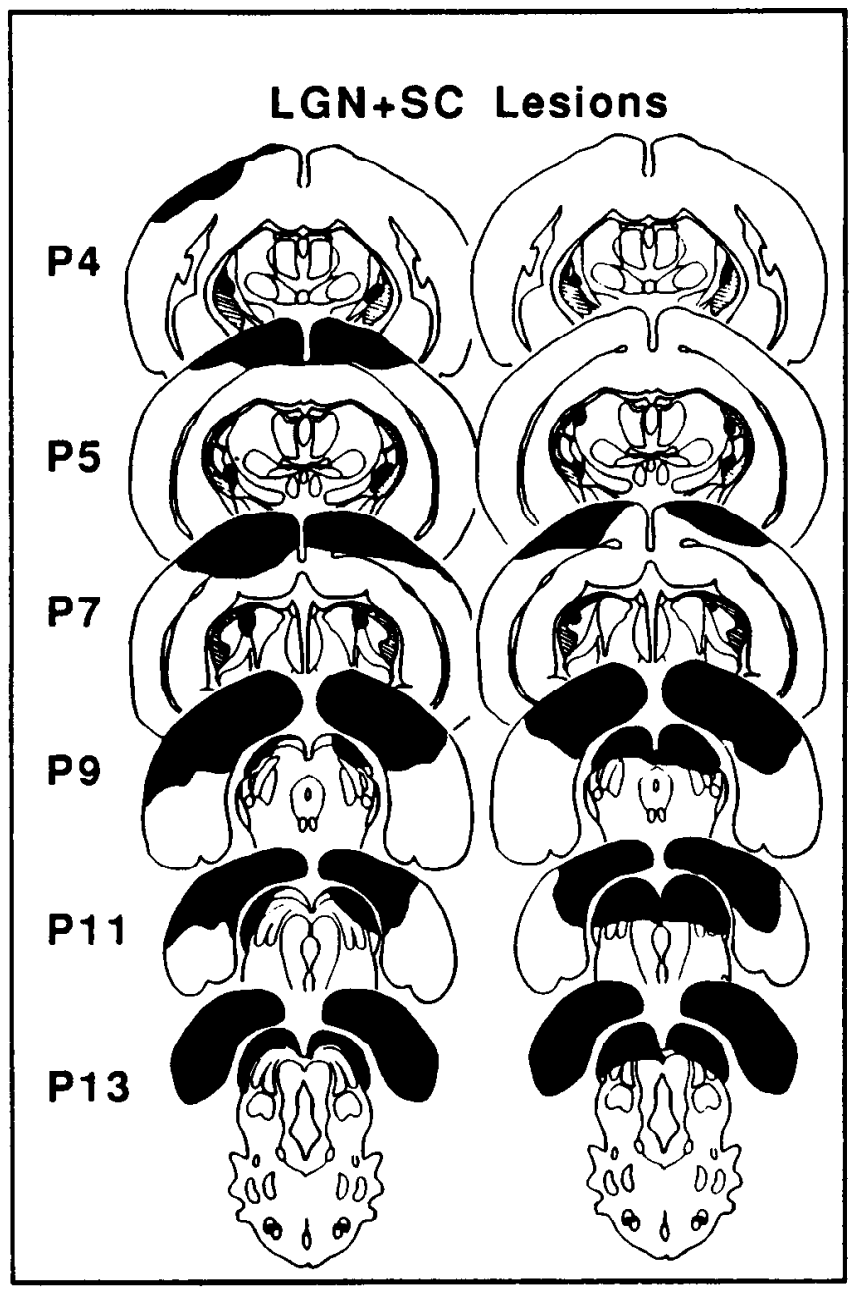

Figure 6. Histological reconstructions of LGN + SC lesions. Columns labled $L G N+S C$ Lesions show the smallest and largest lesions (black) in the LGN + SC group.

Ibotenic acid lesions resulted in little damage to structures adjoining the target areas. Injection of ibotenic acid in the LGN produced slight damage to the reticular nucleus of the thalamus, the zona incerta, and the posterior thalamic complex, including the pulvinar in almost all animals. Injection of ibotenic acid in the Ptc produced slight damage to the medial geniculate nucleus in 2 animals in the Ptc group, in 2 animals in the LGN + Ptc group, and in one in the LGN $+\mathrm{SC}+$ Ptc group. A very small portion of the midbrain reticular formation was damaged in all animals in these groups.

Aspirative lesions resulted in considerable damage to structures adjoining the target areas. Aspiration of the visual cortex extended to cover approximately $20 \%$ of the retrosplenial cortex in the LGN and LGN + SC groups. Aspiration of the SC resulted in the removal of approximately $30 \%$ of the deep layers in all groups for which the SC was a target area (SC, LGN + SC, SC + Ptc, and LGN + SC + Ptc). In the SC and SC + Ptc groups, aspiration of the $\mathrm{SC}$ resulted in partial removal of the visual cortex (approximately 40\%). This damage at the visual cortex was approximately half the size of that produced in the LGN, $\mathrm{LGN}+\mathrm{Ptc}$, and LGN + SC + Ptc groups (the groups in which the visual cortex was a target area).

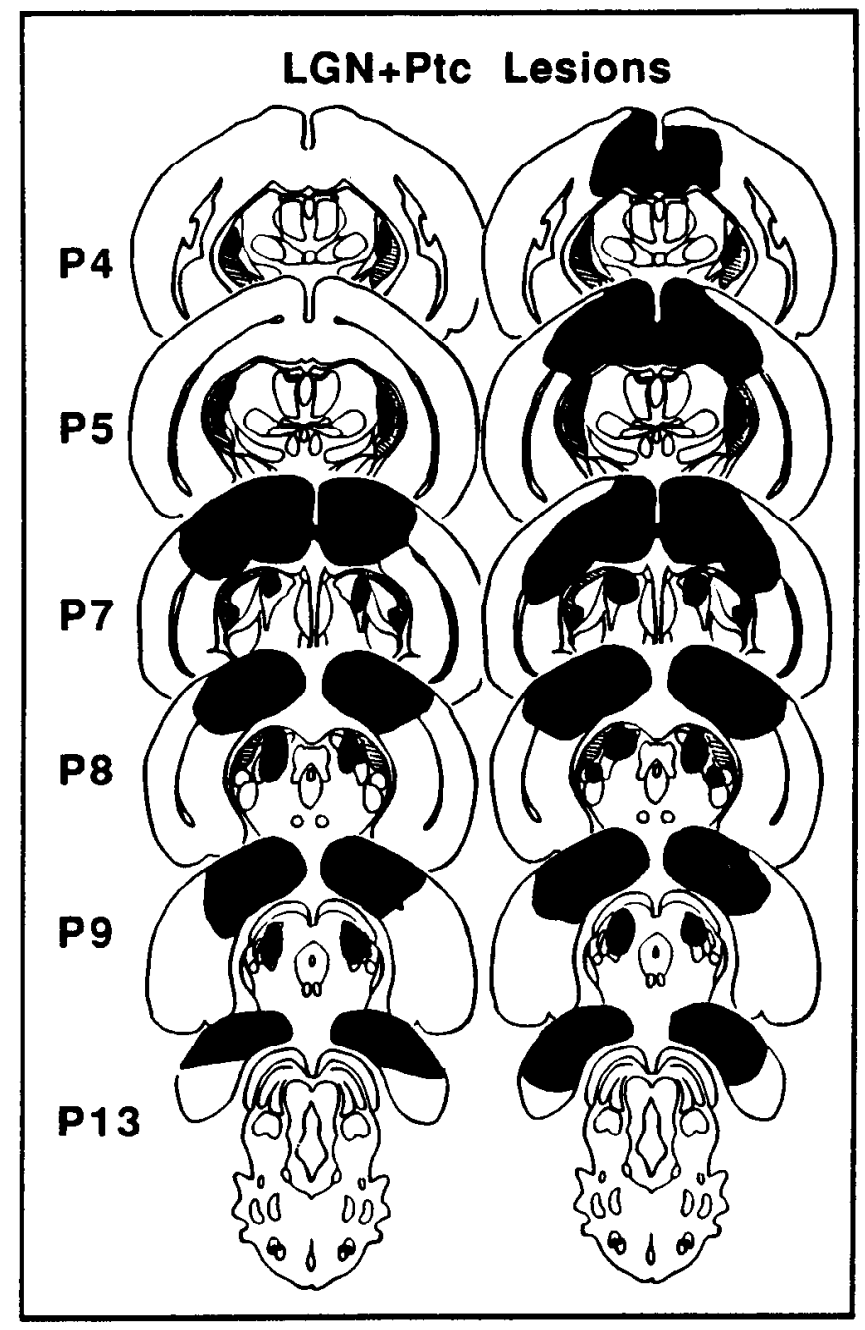

Figure 7. Histological reconstructions of LGN + Ptc lesions. Columns labeled $L G N+$ Ptc Lesions show the smallest and largest lesions (black) in the LGN + Ptc group.

\section{Discussion}

The results of the present study indicate that parallel pathways can individually conduct information about a visual $C S$ to brain areas critical for acquisition of the classically conditioned NM response. Single lesions to any one of the 3 target systems (LGN, $\mathrm{SC}, \mathrm{Ptc})$ did not alter the rate of conditioning. Furthermore, double lesions to any 2 of the systems did not prevent conditioning, although LGN + SC lesions significantly retarded acquisition. When all 3 systems were lesioned, however, animals never acquired to the visual CS, although they successfully conditioned to an auditory CS. The finding that the combined $\mathrm{LGN}+\mathrm{SC}$ lesion produced a significant slowing of acquisition suggests that the pretectal nuclei, although capable of supporting conditioning, are not as efficient as the LGN and SC systems in transmitting visual $\mathrm{CS}$ information during NM conditioning.

The finding that parallel visual pathways are individually capable of supporting NM conditioning to a visual CS is similar to the findings of Cohen (1982), who used the heart-rate preparation in pigeon. Cohen found that single lesions of the principal optic nucleus, nucleus rotundus, and pretectal region did not affect conditioning rates. Double lesions of any 2 of the 3 


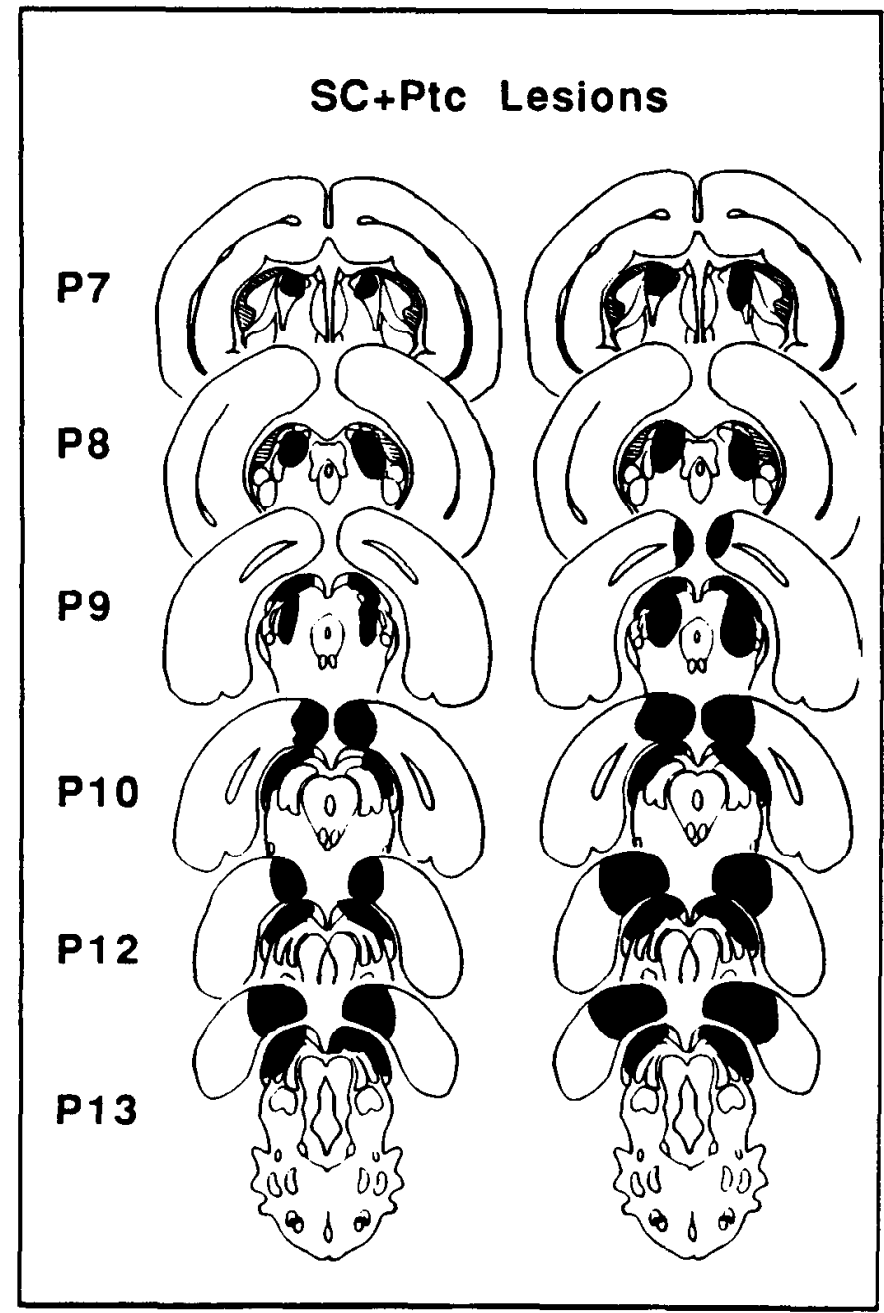

Figure 8. Histological reconstructions of $\mathrm{SC}+$ Ptc lesions. Columns labeled $S C+$ Ptc Lesions show the smallest and largest lesions (black) in the SC + Ptc group.

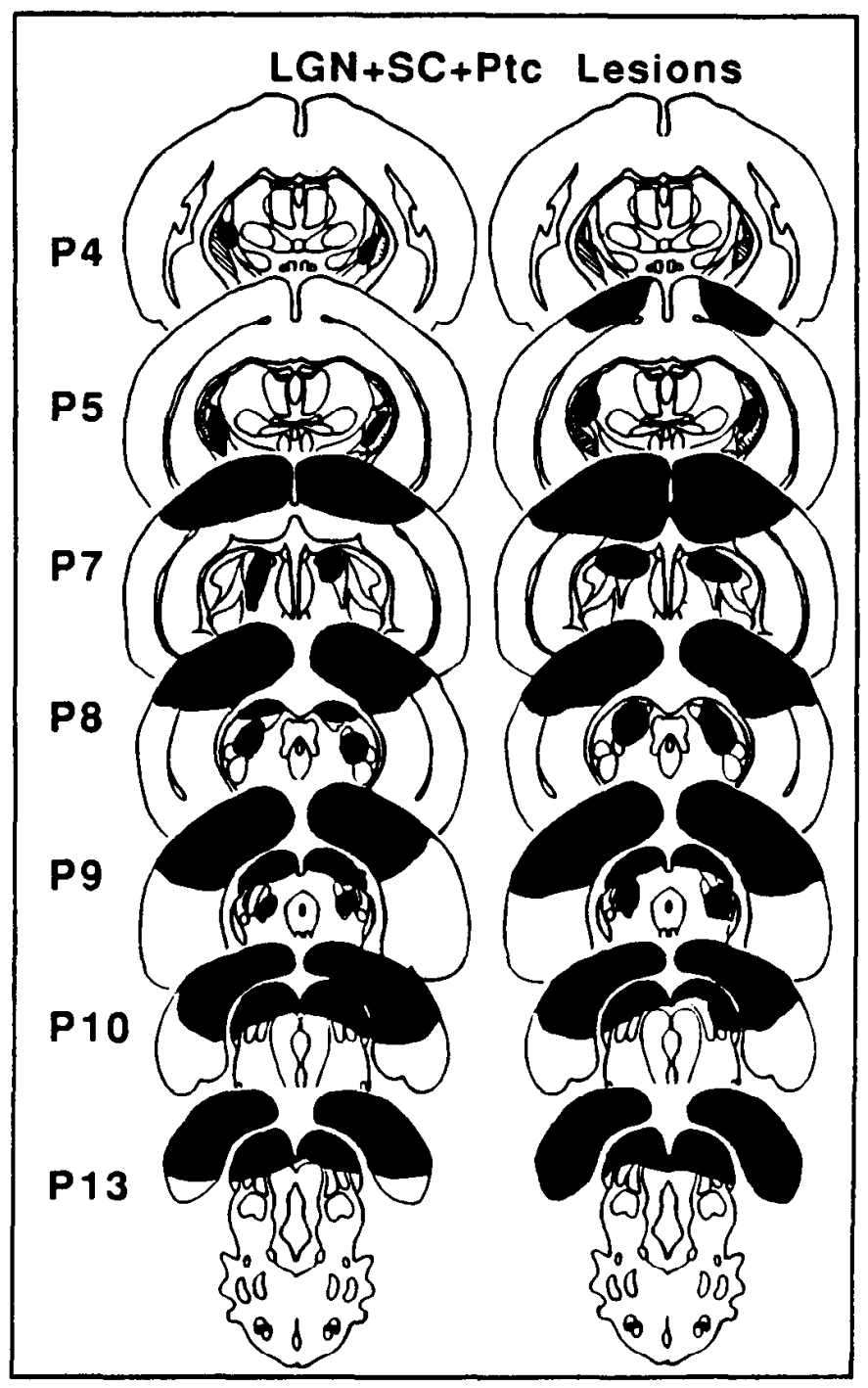

Figure 9. Histological reconstructions of triple lesions. Columns labeled $L G N+S C+P t c$ Lesions show the smallest and largest lesions (black) in the triple lesion group.

\begin{tabular}{|c|c|c|c|c|c|}
\hline Area lesioned & Dorsal LGN & Ventral LGN & Visual cortex & SC & Ptc \\
\hline LGN & $\begin{array}{l}40 \\
(0-85)\end{array}$ & $\begin{array}{l}84 \\
(65-100)\end{array}$ & $\begin{array}{l}93 \\
(90-100)\end{array}$ & - & - \\
\hline SC & - & - & $\begin{array}{l}45 \\
(30-70)\end{array}$ & $\begin{array}{l}84 \\
(75-90)\end{array}$ & - \\
\hline Ptc & - & - & - & - & $\begin{array}{l}79 \\
(70-85)\end{array}$ \\
\hline $\mathrm{LGN}+\mathrm{SC}$ & $\begin{array}{l}33 \\
(25-40)\end{array}$ & $\begin{array}{l}80 \\
(65-85)\end{array}$ & $\begin{array}{l}88 \\
(80-95)\end{array}$ & $\begin{array}{l}95 \\
(80-100)\end{array}$ & - \\
\hline LGN + Ptc & $\begin{array}{l}23 \\
(15-50)\end{array}$ & $\begin{array}{l}91 \\
(75-100)\end{array}$ & $\begin{array}{l}85 \\
(80-95)\end{array}$ & - & $\begin{array}{l}77 \\
(65-80)\end{array}$ \\
\hline $\mathrm{SC}+\mathrm{Ptc}$ & - & - & $\begin{array}{l}35 \\
(30-50)\end{array}$ & $\begin{array}{l}92 \\
(85-100)\end{array}$ & $\begin{array}{l}72 \\
(65-85)\end{array}$ \\
\hline $\mathrm{LGN}+\mathrm{SC}+\mathbf{P t c}$ & $\begin{array}{l}21 \\
(10-40)\end{array}$ & $\begin{array}{l}85 \\
(75-95)\end{array}$ & $\begin{array}{l}90 \\
(80-95)\end{array}$ & $\begin{array}{l}90 \\
(85-100)\end{array}$ & $\begin{array}{l}75 \\
(65-85)\end{array}$ \\
\hline
\end{tabular}



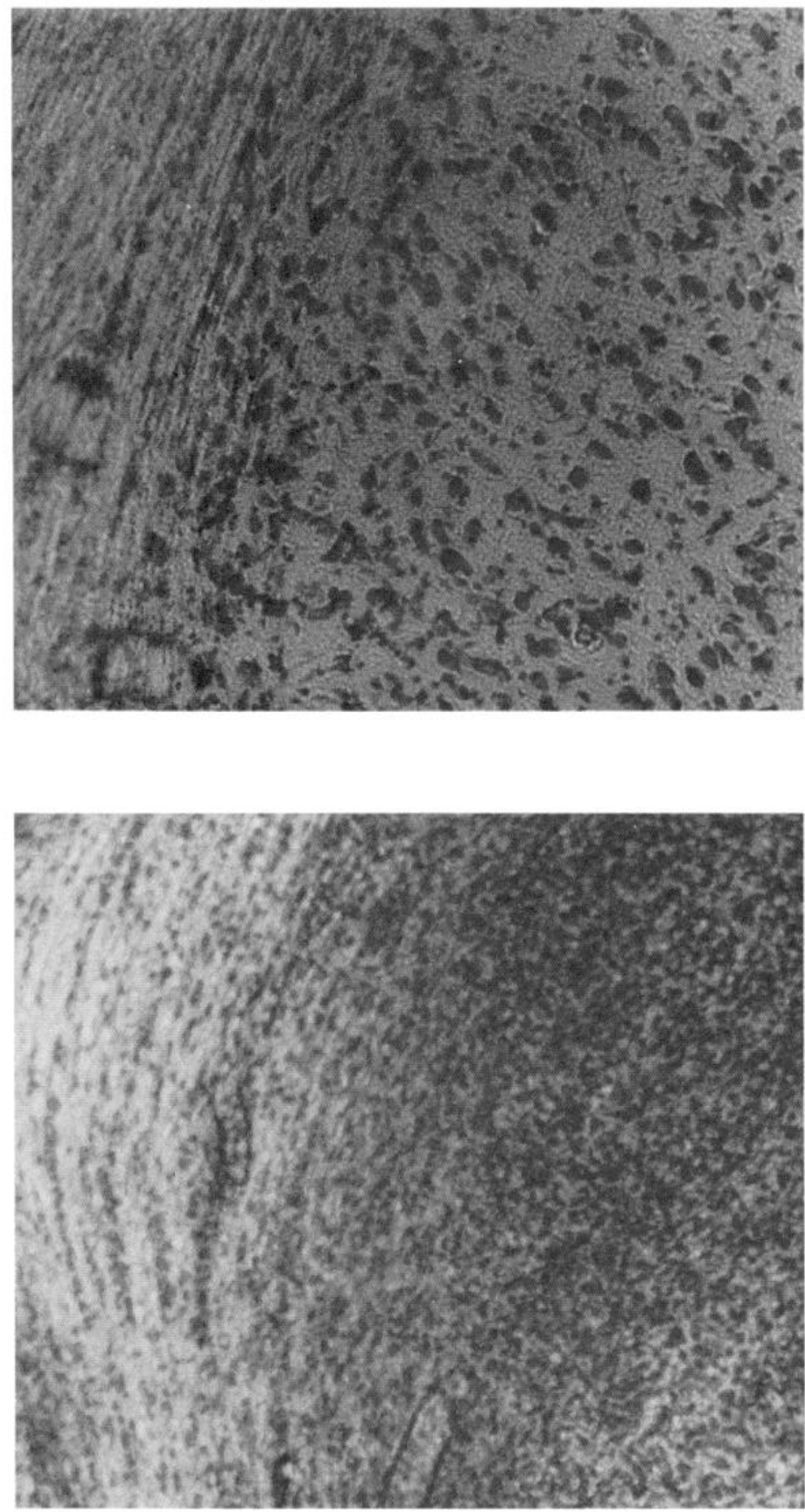

Figure 10. a, Photomicrograph of the ventral LGN and optic tract (at left side of plate) of an intact animal. $b$, Photomicrograph of the ventral LGN and optic tract of a lesioned animal.

structures produced only short-lasting deficits. When all 3 structures were lesioned, however, heart-rate conditioning was prevented. The avian principal optic nucleus and the pretectal region are homologous to the LGN and the pretectal area in mammals, respectively, and the nucleus rotundus is a direct projection site for the optic tectum, which is homologous to the mammalian SC. The similarity of the findings with 2 different preparations suggests that parallel pathways transmitting CS information may be an important structural characteristic of visual systems or even of sensory systems in general.
Following identification of those visual structures critical for conduction of the visual CS, the next step in tracing the circuit underlying NM classical conditioning is to link the visual CS pathway to those central brain structures that are known to be essential components of the circuit. The model proposed by Thompson and colleagues (Steinmetz et al., 1985b; WoodruffPak and Thompson, 1985) states that CS information is relayed from primary sensory systems (e.g., the visual system) to precerebellar nuclei and then to the cerebellum via mossy fibers through the middle cerebellar peduncle. The most likely can- 

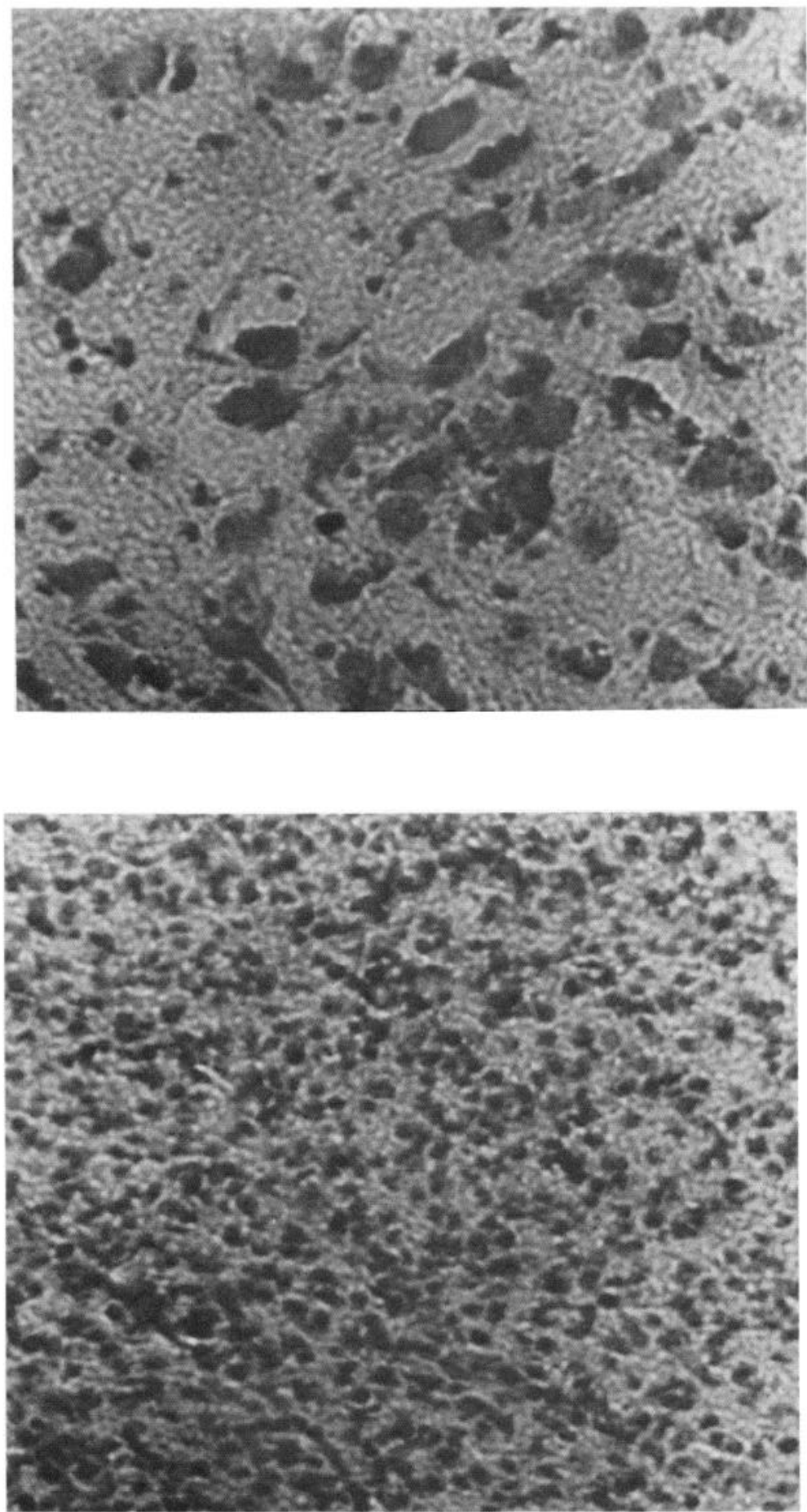

a
Figure 11. a, Photomicrograph of the anterior pretectal nucleus of an intact animal. $b$, Photomicrograph of the anterior pretectal nucleus of a lesioned animal. didates among the precerebellar nuclei for the visual CS pathway are those found in the ventral pons. These nuclei are the dorsolateral pontine nucleus (DLPN, which is dorsal and lateral to the pyramidal tract), the rostral pontine nuclei (which are ventral and medial to the pyramidal tract), and the paramedian pontine nucleus (which lies near the midline at the level of the DLPN).

Evidence implicating these 3 structures comes from both physiological and anatomical studies. A significant population of cells in the DLPN and rostral pons in cat are responsive to visual stimulation with onset latencies of 20-26 msec (Mower et al., 1979) and approximately $25 \mathrm{msec}$ (Glickstein et al., 1972), respectively. The short latencies indicate that the visual input is probably projected to these cells directly from primary visual structures. Indeed, all 3 pontine areas have been shown to receive direct inputs from several primary visual structures. First, in cat several areas of the visual cortex project to cells in the rostral portion of the ventral pons (Brodal, 1972a, b; Baker et al., 1975; Mower et al., 1980; Robinson et al., 1984). These visually sensitive pontine cells, in turn, project primarily to the contralateral cerebellar hemisphere (Brodal and Jansen, 1946; 
Figure 12. Pathways by which visual information can be projected from primary visual structures to the cerebellum.

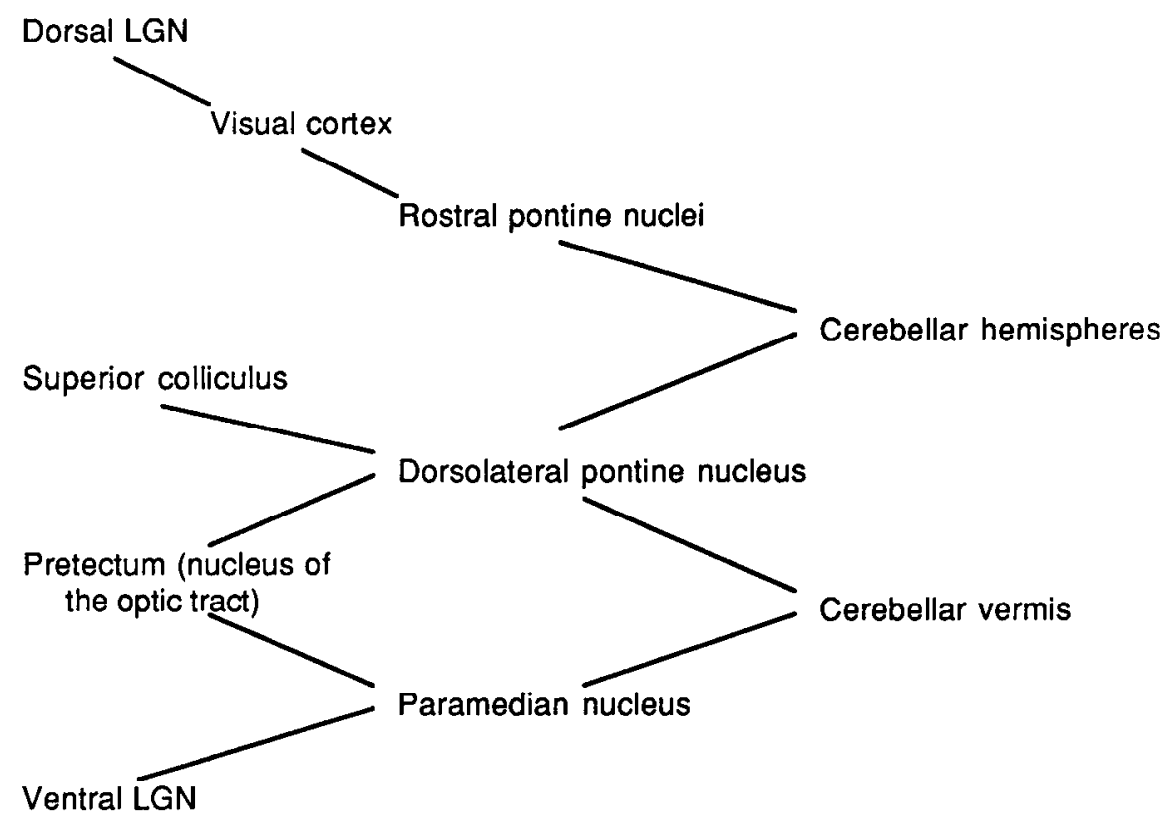

Mower et al., 1980; Robinson et al., 1984). Second, in rabbit, cat, and rat, cells in the superficial and deep layers of the SC project to the DLPN (Kawamura and Brodal, 1973; Graham, 1977; Mower et al., 1979; Holstege and Collewijn, 1982), which then projects primarily to the cerebellar vermis and ipsilateral cerebellar hemisphere (Brodal and Jansen, 1946; Kawamura and Brodal, 1973; Hoddevik et al., 1977; Mower et al., 1980; Yeo et al., 1985b). Third, in cat and rat, the ventral LGN projects to the paramedian pontine nucleus (Edwards et al., 1974; Graybiel, 1974b; Swanson et al., 1974; Ribak and Peters, 1975). Cells from the paramedian nucleus project to the cerebellar vermis in a pattern that is very similar to the projection of the DLPN (Mower et al., 1980). Fourth, in rabbit, the nucleus of the optic tract, one of the pretectal nuclei, projects to both the DLPN and the paramedian nucleus (Graybiel, 1974a; Weber and Harting, 1980; Holstege and Collewijn, 1982). The projections of the LGN, SC, Ptc, and visual cortex to the cerebellum can be summarized as in Figure 12.

In sum, the precerebellar areas of the ventral pons (the DLPN, the rostral pontine nuclei, and the paramedian nucleus) receive massive visual input. Furthermore, stimulation of one of these areas, the DLPN, can serve as an effective CS during NM response conditioning (Steinmetz et al., 1985a, b). This implies that physiological activation of cells in the DLPN by a visual stimulus could also serve as an effective CS. Although indirect, the aforementioned anatomical and physiological studies indicate that the DLPN is a probable site through which critical visual CS information is relayed to the cerebellum during NM response conditioning. The finding that lesions of the DLPN do not abolish conditioned responses to a visual CS, however (Steinmetz et al., 1986), indicates that this area is not the only one involved in transmitting information about a visual CS to the cerebellum. Anatomical and physiological studies also indicate that the rostral and/or the paramedian pontine nuclei may be involved. Additional information, however, is needed before the precise role of these pontine areas can be determined. It is necessary to determine if these areas are critical for the transmission for visual CS information. That is, will lesions of these pontine nuclei prevent acquisition of the conditioned NM response to a light CS? If training to a visual CS is blocked by lesions to one or more of these pontine nuclei, then it would be necessary to determine if visually responsive precerebellar cells in the critical areas show learning-dependent changes during NM response conditioning. Determining whether learning-dependent changes take place in the pons and in their inputs would permit a more accurate interpretation of any neuronal plasticity in the cerebellum.

In conclusion, information about a visual CS (whole-field illumination) can be projected via multiple pathways to the circuit that is essential for classical conditioning of the NM response. Consequently, conditioning can occur if at least one of the primary visual structures-the LGN, SC, or pretectal area -is intact. Although several alternatives exist, one possible route for the transmission of visual $\mathrm{CS}$ information is from primary visual structures to the cerebellum via precerebellar nuclei in the ventral pons.

\section{References}

Albus, J. S. (1971) A theory of cerebellar function. Math Biosci. 10: 25-61.

Baker, J., A. Gibson, M. Glickstein, and J. Stein (1975) Visual cells in the pontine nuclei of the cat. J. Physiol. (Lond.) 255: 415-433.

Berthier, N. E., and J. W. Moore (1983) The nictitating membrane response: An electrophysiological study of the abducens nerve and nucleus and the accessory abducens nucleus in rabbit. Brain Res. 258: 201-210.

Brodal, A., and J. Jansen (1946) The ponto-cerebellar projection in cat. J. Comp. Neurol. 84: 31-118.

Brodal, P. (1972a) The corticopontine projection from the visual cortex in the cat. I. The total projection and the projection from area 17. Brain Res. 39: 297-317.

Brodal, P. (1972b) The corticopontine projection from the visual cortex in the cat. II. The projection from areas 18 and 19. Brain Res. 39: 319-335.

Cegavske, C. F., R. F. Thompson, M. M. Patterson, and I. Gormezano (1976) Mechanisms of efferent neuronal control of the reflex nictitating membrane response in the rabbit. J. Comp. Physiol. Psychol. 90: 411-423.

Cohen, D. H. (1982) Central processing time for a conditioned response in a vertebrate model system. In Conditioning: Representations 
of Involved Neural Functions, C. D. Woody, ed., pp. 517-534, Plenum, New York.

Disterhoft, J. F., K. J. Quinn, C. Weiss, and M. T. Shipley (1985) The role of accessory abducens in control of conditioned eye retraction/ nictitating membrane extension in rabbit. J. Neurosci. 5: 941-950.

Edwards, S. B., A. C. Rosenquist, and L. A. Palmer (1974) An autoradiographic study of ventral lateral geniculate projections in the cat. Brain Res. 72: 282-287.

Glickstein, M., J. Stein, and R. A. King (1972) Visual input to the pontine nuclei. Science 178: 1110-1111.

Gormezano, I., N. Schneiderman, E. Deaux, and I. Fuentes (1962) Nictitating membrane: Classical conditioning and extinction in the albino rabbit. Science 138: 33-34.

Graham, J. (1977) An autoradiographic study of the efferent connections of the superior colliculus in the cat. J. Comp. Neurol. 173: 629654

Graybiel, A. M. (1974a) Some efferents of the pretectal region in the cat. Anat. Rec. 178: 365.

Graybiel, A. M. (1974b) Visuo-cerebellar and cerebello-visual connections involving the ventral lateral geniculate nucleus. Exp. Brain Res. 20: 303-306.

Haley, D. A., D. G. Lavond, and R. F. Thompson (1983) Effects of contralateral red nucleus lesions on retention of the classically conditioned nictitating membrane/eyelid response. Soc. Neurosci. Abstr. 9: 643.

Harvey, J. A., T. Land, and S. E. McMaster (1984) Anatomical study of the rabbit's corneal-VIth nerve reflex: Connections between cornea, trigeminal sensory complex, and the abducens and accessory abducens nuclei. Brain Res. 301: 307-321.

Hoddevik, G. H., A. Brodal, K. Kawamura, and T. Hashikawa (1977) The pontine projection to the cerebellar vermal visual area studied by means of the retrograde axonal transport of horseradish peroxidase. Brain Res. 123: 209-227.

Holstege, G., and H. Collewijn (1982) The efferent connections of the nucleus of the optic tract and the superior colliculus in the rabbit. J. Comp. Neurol. 209: 139-175.

Kawamura, K., and A. Brodal (1973) The tectopontine projection in cat: An experimental anatomical study with comments on pathways for teleceptive impulses to the cerebellum. J. Comp. Neurol. 149: 371-390.

Lavond, D. G., D. S. Woodruff-Pak, and R. F. Thompson (1984a) Initial identification of the essential brainstem auditory pathway necessary for classical conditioning in the rabbit nictitating membrane (NM)/eyelid response. Soc. Neurosci. Abstr. 10:131.

Lavond, D. G., D. A. McCormick, and R. F. Thompson (1984b) A nonrecoverable learning deficit. Physiol. Psychol. 12: 103-110.

Lewis, J., J. J. LoTurco, and P. R. Solomon (1987) Middle cerebellar peduncle lesions disrupt acquisition and retention of the rabbit's conditioned nictitating membrane response. Behav. Neurosci. 101: 151157.

Marr, D. (1969) A theory of cerebellar cortex. J. Physiol. (Lond.) 202: $437-470$.

McCormick, D. A., and R. F. Thompson (1983) Possible neuronal substrate of classical conditioning within the mammalian CNS: Dentate and interpositus nucleus. Soc. Neurosci. Abstr. 9: 643.

McCormick, D. A., P. E. Guyer, and R. F. Thompson (1982) Superior cerebellar peduncle lesions selectively abolish the ipsilateral classically conditioned nictitating membrane/eyelid response of the rabbit. Brain Kes. 245: 347-350.
Mower, G., A. Gibson, and M. Glickstein (1979) Tectopontine pathway in the cat: Laminar distribution of cells of origin and visual properties of target cells in dorsolateral pontine nucleus. J. Neurophysiol. $42: 1-15$.

Mower, G., A. Gibson, F. Robinson, J. Stein, and M. Glickstein (1980) Visual pontocerebellar projections in the cat. J. Neurophysiol. 43: 355-366.

Ribak, C. E., and A. Peters (1975) An autoradiographic study of the projections from the lateral geniculate body of the rat. Brain Res. 92 : 341-368.

Robinson, F. R., J. L. Cohen, J. May, A. K. Sestokas, and M. Glickstein (1984) Cerebellar targets of visual pontine cells in the cat. J. Comp. Neurol. 223: 471-482.

Rosenfield, M. E., and J. W. Moore (1983) Red nucleus lesions disrupt the classically conditioned nictitating membrane response in rabbits. Behav. Brain Res. 10: 393-398.

Rosenfield, M. E., A. Devydaitis, and J. Moore (1985) Brachium conjunctivum and rubrobulbar tract: Brainstem projections of red nucleus essential for the conditioned nictitating membrane response. Physiol. Behav. 34: 751-759.

Skelton, R. W., N. H. Donegan, and R. F. Thompson (1984) Superior colliculus lesions disrupt classical conditioning to visual but not auditory stimuli. Soc. Neurosci. Abstr. 10: 132.

Steinmetz, J. W., D. G. Lavond, and R. F. Thompson (1985a) Classical conditioning of the rabbit eyelid response with mossy fiber stimulation as the conditioned stimulus. Bull. Psychon. Soc. 23: 245-248.

Steinmetz, J. W., D. G. Lavond, and R. F. Thompson (1985b) Classical conditioning of skeletal muscle responses with mossy fiber stimulation CS and climbing fiber stimulation US. Soc. Neurosci. Abstr. 11:982.

Steinmetz, J. W., C. G. Logan, D. J. Rosen, D. G. Lavond, and R. F. Thompson (1986) Lesions in the pontine nuclear region selectively abolish classically conditioned eyelid responses in rabbits. Soc. Neurosci. Abstr., 12: 753 .

Swanson, L. W., W. M. Cowan, and E. G. Jones (1974) An autoradiographic study of the efferent connections of the ventral lateral geniculate nucleus in the albino rat and the cat. J. Comp. Neurol. 156: $143-164$

Thompson, J. M., C. N. Woolsey, and S. A. Talbot (1950) Visual areas I and II of cerebral cortex of rabbit. J. Neurophysiol. 13: 277 288.

Urban, I., and P. Richard (1972) A Stereotaxic Atlas of the New Zealand Rabbit's Brain, Thomas, Springfield, IL

Weber, J. T., and J. K. Harting (1980) The efferent projections of the pretectal complex: An autoradiographic and horseradish peroxidase analysis. Brain Res. 194: 1-28.

Woodruff-Pak, D. S., and R. F. Thompson (1985) Classical conditioning of the eyelid response in rabbits as a model system for the study of brain mechanisms of learning and memory in aging. Exp. Aging Res. 11: 109-122.

Yeo, C. H., M. J. Hardiman, M. Glickstein, and I. S. Russell (1982) Lesions of cerebellar nuclei abolish the classically conditioned nictitating membrane response. Soc. Neurosci. Abstr. 8: 22.

Yeo, C. H., M. J. Hardiman, and M. Glickstein (1985a) Classical conditioning of the nictitating membrane response of the rabbit. I. Lesions of the cerebellar nuclei. Exp. Brain Res. 60:87-98.

Yeo, C. H., M. J. Hardiman, and M. Glickstein (1985b) Classical conditioning of the nictitating membrane response of the rabbit. III. Connections of cerebellar lobule HVI. Exp. Brain Res. 60: 114-126. 